\title{
Ultra-Strong Knits for Personal Protective Equipment
}

\author{
Daiva Mikucioniene ${ }^{1}$, Liudmyla Halavska ${ }^{2}{ }^{\circ}$, Svitlana Bobrova ${ }^{2}$, Tetiana Ielina ${ }^{2}$ \\ and Rimvydas Milasius ${ }^{1, *}$ \\ 1 Department of Production Engineering, Kaunas University of Technology, 44249 Kaunas, Lithuania; \\ daiva.mikucioniene@ktu.lt \\ 2 Department of Textile Technology and Design, Kyiv National University of Technologies and Design, \\ 01011 Kyiv, Ukraine; galavska.ly@knutd.edu.ua (L.H.); bobrova.sy@knutd.edu.ua (S.B.); \\ yelina.tv@knutd.edu.ua (T.I.) \\ * Correspondence: rimvydas.milasius@ktu.lt; Tel.: +370-613-73805
}

Received: 23 August 2020; Accepted: 4 September 2020; Published: 7 September 2020

\begin{abstract}
This work focused on the development of ultra-strong knitted fabrics for personal protective equipment used for protection against mechanical damages. Such knits have to have enhanced mechanical strength properties, which strongly depend on knitting pattern and structural characteristics. Six variants of weft knitted structures were developed and knitted from ultra-high molecular weight polyethylene and additional elastomeric component. The elastomeric component was used to increase the elasticity and toughness of knits; however, it had a high influence on mechanical properties, as well. The performed mechanical tests allowed us to identify dependence of mechanical properties, such as breaking force and elongation at break and resistance to abrasion, tearing, cutting and puncture, on architecture and structural parameters of the knits. Obtained results demonstrate that elastomeric component has high influence on mechanical properties knits and can change the principal mechanical behaviour of knits.
\end{abstract}

Keywords: personal protective equipment; ultra-strong knits; mechanical properties; knitted structure; elastomeric component

\section{Introduction}

Production of ultra-strong knits is a promising and important direction for personal protective equipment used to protect the human body from different kinds of threats such as sharp objects. This group of products includes gloves and sleeves protecting various parts of hands, vests, helmets, and long hoses, etc. One of the main characteristics of such products is the enhanced resistance against mechanical damages such as cutting, tearing, puncture, and abrasion. In comparison with woven fabrics, knitted fabrics have the advantage of better designability, being both lightweight and comfortable [1]. In addition, knitted fabrics can ensure good thermal properties, as well as air and water vapour permeability. However, several problems can be faced in the development and production of such knitted products [1,2]. Garments protecting against mechanical injuries usually are manufactured from high-strength fibres such as carbon fibres, aramid fibres, ultra-high molecular weight polyethylene fibres, and glass fibres, etc. [3-5]. Ultra-high molecular weight polyethylene (UHMWPE) is well-known high-performance fibre to produce protective textile material due to its high resistance-to-impact damage [6]. UHMWPE yarns are known as nontoxic and good fatigue resistance. This type of raw material is usually processed on knitting equipment with sinkers, which ensure concentrated execution of individual loop forming. This factor contributes to the unhindered formation of loops of minimum length. In addition to fibre and yarn properties, parameters of fabric structure and geometry play an important role in determining level of personal protection [7]. Nowadays, high-performance fibres are typically used in woven or non-woven forms and significantly less frequently in knitted form. 
Knits from ultra-high strength yarns, usually used for this type of product, can be knitted on knitting machines with sinkers, which ensure concentrated execution of individual loop forming. This safely fixes the yarn during its entry under the needle hook and form loops with constant yarn tension. Knitting difficulties arise because of high rigidity of ultra-high strength yarns and shear strength, i.e., their low capability to resist to high curvature. It is known that loop geometry strongly depends on the raw material of yarns [8]. Knits used for personal protection have to have enhanced mechanical strength properties, which strongly depend on knitting pattern and structural characteristics $[3,9,10]$. On the other hand, garments for personal protection also have to ensure good comfort properties [11]. Recently, consumers of personal protection garments have required high protection in combination with high comfort level. Such garments should be flexible, soft, lightweight, with good air permeability and moisture management, and at the same time resistant to cutting, tearing, puncture, and abrasion [12,13]. Comfort properties can be enhanced very easily by choosing proper knitting patterns and structural parameters $[11,13,14]$. However, enhanced comfort must be reached without compromise and with lower protection levels.

Various technologies are used for the production of personal protective equipment. For bulletproof vests, usually weaving technology is used. The group of knitted products includes gloves, half-gloves, fingertips, handhelds, wristlets, sleeves, and elbow pads, etc. [15]. The behaviour of knitted fabrics during mechanical injuries is different from woven fabrics because of its principally different, loop-based, knitted structure. The cutting and tearing mechanism of the knitted structure is much more complicated due to its specific geometry of structure, and the yarns intrinsic character in the knitted structure, in addition to structural flexibility and their ability to bring more yarns by shearing during cutting $[10,16,17]$. Puncture resistance of knitted fabrics is also, generally difficult, as stitches in the knit are able to take yarn from adjacent stitches. Due to this, a hole opens in the fabric without cutting or tearing the yarns [1].

In this study, the development of ultra-strong knitted fabrics for personal protective equipment and an investigation on their resistance against mechanical damages are presented. Mechanical tests were performed to identify dependence of mechanical properties, such as tensile strength, resistance to tearing, cutting, puncture and abrasion—on structural parameters of the newly developed knits.

\section{Materials and Methods}

Two variants of weft knitted structures with three different loop lengths of each, i.e., six variants in total, were developed and used for experimental tests. Knits of the first structural variant, named as weft plain WP, were knitted from 132 tex linear density ultra-high molecular weight polyethylene (UHMWPE) yarns in plain weft pattern on a flat V-bed weft knitting machine. Knits of the second structural variant, named weft fleece pattern (WPE), were knitted in a plain-fleece pattern from the same UHMWPE yarns in combination with 100 tex linear density elastomeric (EL) yarn, laid as the fleece-yarn in every fourth course in tuck-miss pattern with $1 \times 3$ repeat. Both variants are based on the same single jersey pattern, however, the second structural variant is designed with additionally laid elastomeric yarn in order to improve wearing comfort. Structure with elastomeric yarns gives significantly higher density, and tightness, in addition to higher transversal elasticity of the knit, which ensures better wearing comfort. The single jersey pattern was used because of its lower mass per unit area in comparison with double knitted structures such as rib or interlock. Both investigated structural variants are presented in Figure 1. The main structural parameters of the knitted fabrics are presented in Table 1. Samples of both variants were knitted with three different loop lengths to investigate the influence of loop length on mechanical behaviour of the knits. 


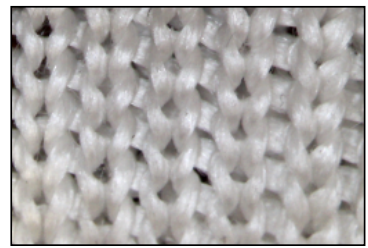

(a)

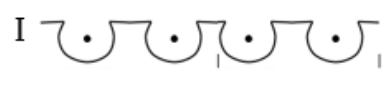

A $\quad$ B $\quad$ C D

(c)

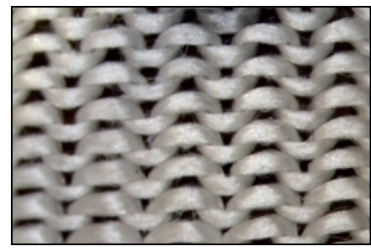

)
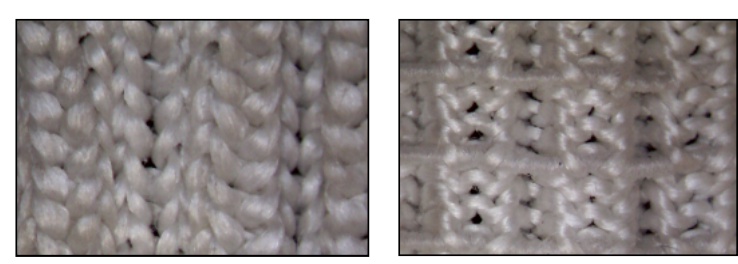

(b)

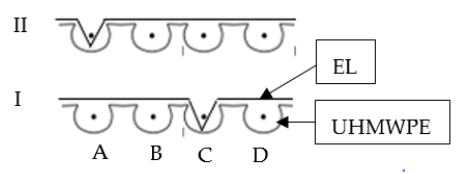

(d)

Figure 1. Images of knitted structure (technical face and technical backsides): (a) weft plain (WP); (b) weft fleece pattern (WPE); (c) knitting diagram of WP; and (d) knitting diagram of WPE.

Table 1. Structural parameters of knitted fabrics.

\begin{tabular}{ccccccc}
\hline $\begin{array}{c}\text { Sample } \\
\text { Code }\end{array}$ & $\begin{array}{c}\text { Loop } \\
\text { Length, } \mathbf{~ m m}\end{array}$ & $\begin{array}{c}\text { Wale Density, } \\
\mathbf{c m}^{-\mathbf{1}}\end{array}$ & $\begin{array}{c}\text { Course } \\
\text { Density, } \mathbf{~ m}^{\mathbf{- 1}}\end{array}$ & $\begin{array}{c}\text { Loop Area, } \\
\mathbf{m m}^{\mathbf{2}}\end{array}$ & $\begin{array}{c}\text { Area Density, } \\
\mathbf{g} / \mathbf{m}^{\mathbf{2}}\end{array}$ & $\begin{array}{c}\text { Thickness, } \\
\mathbf{m m}\end{array}$ \\
\hline WP1 & 7.8 & 4.6 & 7.2 & 3.02 & 343 & 1.41 \\
WP2 & 8.3 & 4.4 & 6.8 & 3.34 & 337 & 1.31 \\
WP3 & 8.8 & 4.2 & 6.4 & 3.72 & 323 & 1.22 \\
WPE1 & 8.6 & 6.4 & 7.0 & 2.23 & 715 & 1.80 \\
WPE2 & 9.1 & 6.0 & 6.4 & 2.60 & 569 & 1.65 \\
WPE3 & 9.6 & 5.0 & 6.0 & 3.34 & 433 & 1.50 \\
\hline
\end{tabular}

To assess the level of protection of the developed knits, the following mechanical properties were investigated: breaking force and elongation at break, resistance to abrasion, tearing, cutting and puncture. Tensile test at break was carried out according to standard LST EN ISO 13934-1:2000 ( $100 \mathrm{~mm} / \mathrm{min}$ speed, $2 \mathrm{~N}$ pretension, $5 \mathrm{kN}$ sensor). Resistance to abrasion was performed according to standard EN 388:2003 by using $300 \mathrm{~g} / \mathrm{m}^{2}$ glass paper as an abrasive material. A tearing test in two directions, i.e., along the wales and courses, was performed according to standard EN 388:2003 and puncture test was performed according to standard EN 863:1995. In order to determine the load required for cutting through textile material with the edge of a blade, a cutting test was performed according to standard DSTU ISO 13997:2001 at a cut length of $20 \mathrm{~mm}$. The coefficient of variation in all cases did not exceed $7 \%$.

After knitting, all specimens were kept in standard atmosphere conditions for $48 \mathrm{~h}$ according to standard EN ISO 139:2005 in order to reach the relaxed state.

\section{Results and Discussion}

\subsection{Tensile Strength}

The tensile test of the newly developed knitted fabrics was performed in order to determine the influence of the elastomeric element in plain structure and loop length on the tensile strength, i.e., breaking force and elongation at break. The results of the breaking tests are presented in Figure 2 . 
(a)
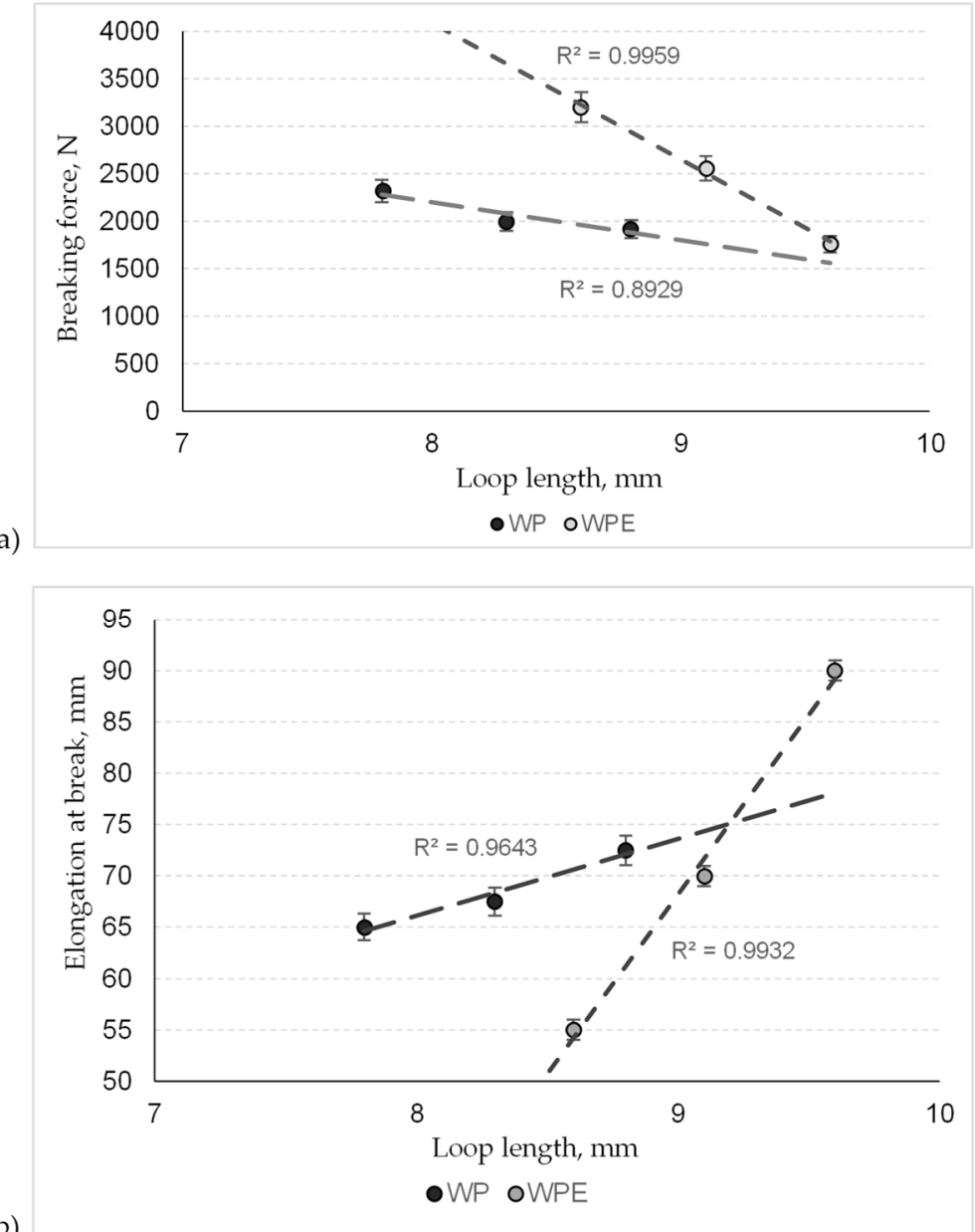

Figure 2. Tensile characteristics: (a) breaking force and (b) elongation at break.

The obtained results clearly demonstrate that the loop length as well as elastomeric element in the knitted pattern have significant influence on the tensile characteristics of the knits. This was also proved by other researchers $[10,12]$. By increasing the loop length, the breaking force linearly decreases, while elongation at the break linearly increases. The breaking force leads to a densification of the structure due to the redistribution of the yarn in the neighbouring loops. It was found that the increase in the loop length of the plain knits with elastomeric tuck-miss laid yarn (WPE) had significantly higher influence on the decrease of the breaking force and increased the elongation at break than of the weft plain knits without the elastomeric yarn (WP). The $11.4 \%$ increase of the loop length in the WP group knits leads to the $20.8 \%$ decrease of the breaking force and $10.3 \%$ increase of the elongation at break, whereas the similar (10.4\%) loop length increase in the WPE group knits leads to even $81.8 \%$ decrease of the breaking force and $38.9 \%$ increase of the elongation at break. It means that even small changes in the loop length of such fabrics with elastomeric fleece yarn in the structure can give high impact on the tensile strength.

\subsection{Cut Resistance}

The goal of the cut resistance tests was to determine the load required for cutting through knitted fabric with the edge of the $20 \mathrm{~mm}$ length blade. The test results are presented in Figure 3. 


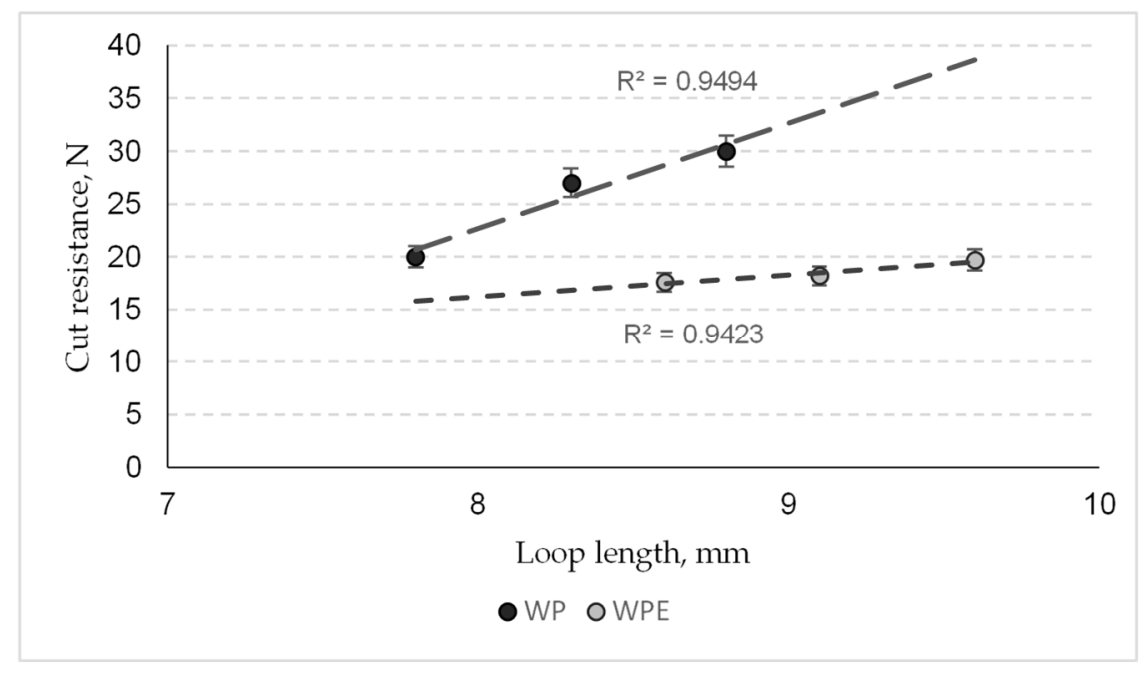

Figure 3. Cut resistance.

It was found that the higher loop length determines higher cut resistance. The increase of the loop length of the plain structure WP by $11.4 \%$ leads to the increase of the cutting through force by $33.3 \%$. However, the similar increase of the loop length (10.4\%) in the WPE structure with the elastomeric yarn caused approx. three times lower increases of the cut resistance-therefore, the cut resistance increased by only $10.7 \%$. The obtained results demonstrate that the lower stitch density (caused by the higher loop length) leads to the higher coefficient of slippage due to the deflection of the textile material under the influence of the blade pressure. Therefore, the loose-knitted structure resists the mechanical action of the cutting force of the blade more effectively.

\subsection{Tearing Resistance}

The tearing test was performed in two directions-longitudinal (along the wales) and transversal (along the courses). It was found that values of the tearing force vary in the ranges of 217-227 N (with a 5\% relative error of measurements), irrespective of the tearing direction, knitting structure and difference in the loop length. Images of the specimens after the tearing test are presented in Figure 4 . The character of knitted samples deformation under the action of the tearing load is different from the woven fabrics and has to be taken into account. During the first stage of the tearing along the wales, unknitting of the loops at the point of maximum stress was observed. As a result of this process, straight segments of the unknitted yarn appears in several courses. During the next stage, these straight segments start to counteract against the tearing load, while the parts of the specimen fixed in the top and bottom clamps-"legs" — curl to the technical-back side along the courses. Finally, the sample breaks in the area of the curled "legs" of the specimen, however, the main part of the specimen remains unimpaired.

A similar situation was observed when a tearing load acts along the courses (Figure 4). When a tearing force is applied along the courses, at the initial stage, unknitting of stitches along the courses occurs in the "legs" of the specimen at the point of maximum stress. The "legs", fixed in the top and bottom clamps, curl to the technical-face side along the wales. In this case the sample finally breaks also in the area of the curled "legs". The unknitted parts of the yarn counteract against the tearing load; therefore, the specimen is not torn completely but only the "leg" breaks. The principal behaviour during the tearing test of the WP and WPE knits is similar, however, the elastomeric fleece yarn used in the WPE knitted fabrics prevents unknitting of stitches under the influence of tearing force applied both along the wales, and along courses. 


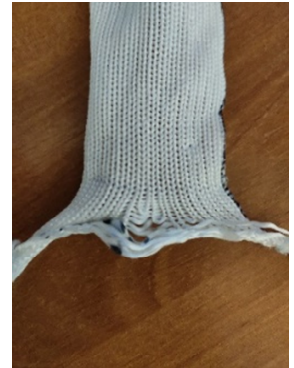

WP

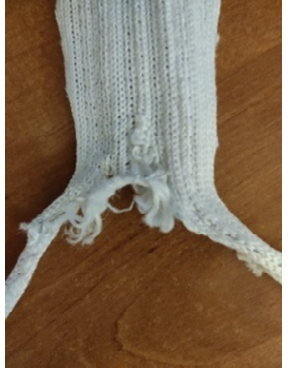

WPE

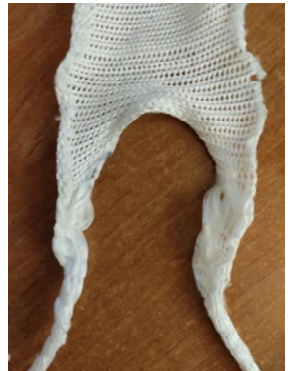

WP

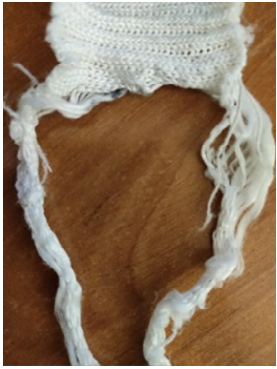

WPE

Tearing in the wale direction

Tearing in the course direction

Figure 4. Knitted specimens after the tearing test.

\subsection{Puncture Resistance}

In order to investigate puncture resistance of the WP and WPE knitted fabrics, the puncture tests were carried out. In this case, two characteristics are important-a high of deformation during puncture and a force at the moment of puncture. The obtained results are presented in Figure 5.
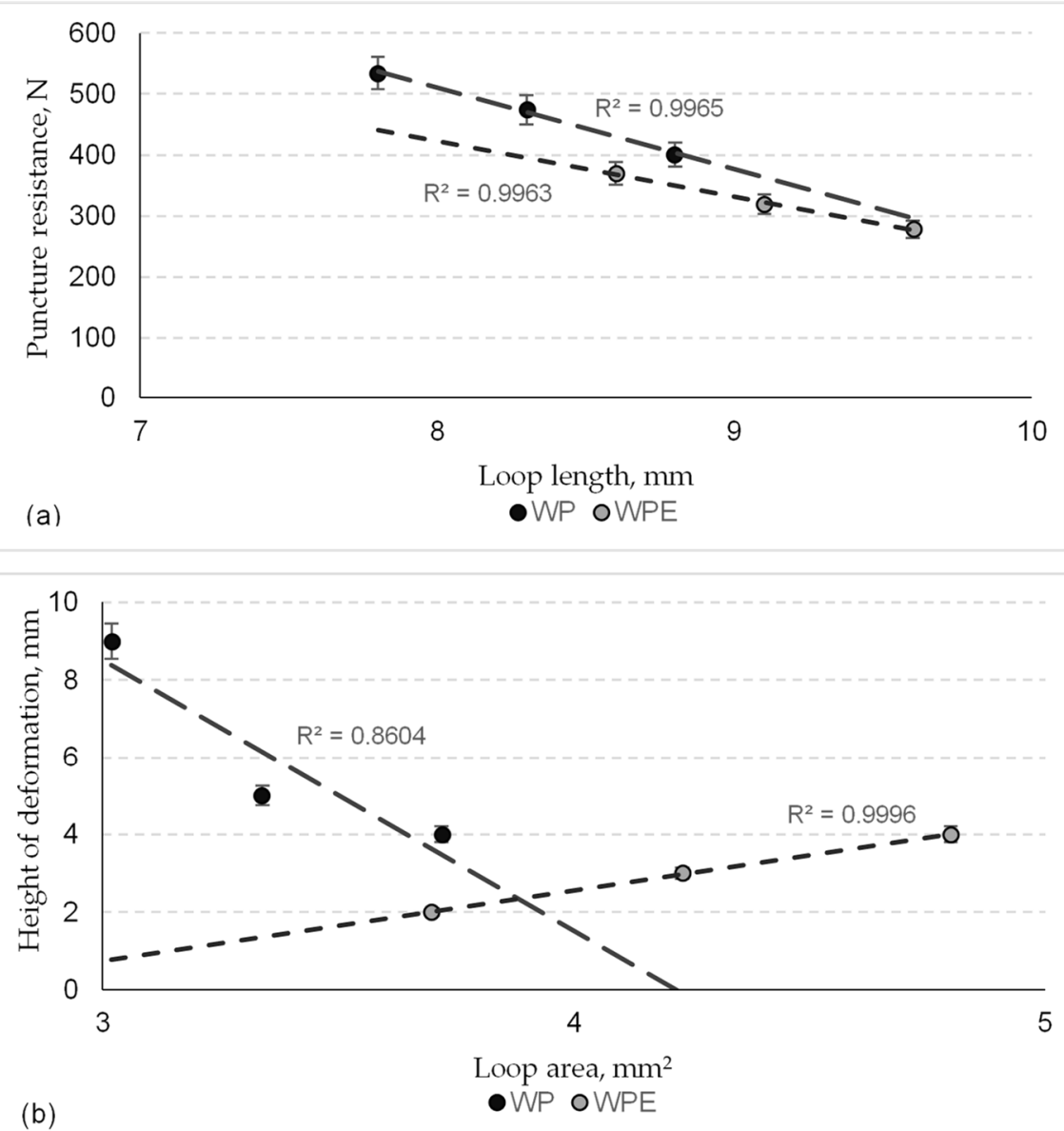

Figure 5. Puncture resistance (a) and height of deformation (b).

The data presented in Figure 5a demonstrate that increase in the loop length causes the decrease in the puncture resistance. The increase of the loop length from $7.8 \mathrm{~mm}$ up to $8.8 \mathrm{~mm}$ (i.e., $11.4 \%$ ) in the WP type knitted fabrics leads to the decrease in the puncture resistance by $33.3 \%$. In addition, the $10.4 \%$ increase in the loop length of the WPE type knits leads to the $32.8 \%$ decrease in puncture 
resistance. To conclude, the $1 \mathrm{~mm}$ decrease of a loop length in a knitted structure can determine approx. $33 \%$ higher resistance to puncture. The total puncture resistance of the plain structure WP type fabrics is higher than of the WPE fabrics with elastomeric yarn even when the loop length in both fabrics (WP3 and WPE1) is very similar. It can be explained by the different high of deformation during the puncture. During puncture of knitted fabrics, stitches in the knit usually take yarn from adjacent stitches and the height of deformation is relatively big. From the data presented in Figure $5 \mathrm{~b}$ it is evident that plain structure fabric WP1 with higher stitch density is deformed in high level (even $9 \mathrm{~mm}$ ) before the fabric is punctured. This high deformation is obtained due to the yarn movement from the adjacent stitches. However, when stitch density decreases (due to increased loop length) the high of deformation gradually decreases, too. The $11.4 \%$ (1 $\mathrm{mm}$ in total) increase in the loop length of the WP type specimens caused a $125 \%$ decrease of the maximum deformation at the moment of puncture. This can be explained by the fact that looser knitted structure may be not broken during the puncture; stitches in a knit move apart each other and the hole forms due to redistribution of the yarn in adjacent courses and wales. However, there is a different situation with the fleecy knitted structures WPE with the elastomeric yarn. By increasing the loop length (i.e., decreasing the stitch density in the fabric) the height of the deformation increases, too. The $10.4 \%$ increased loop length ( $1 \mathrm{~mm}$ in total) determined a 100\% higher maximum deformation at the moment of puncture. The fleece pattern structure has higher tightness than the plain fabric because of the fleece yarn which forms tucks and floats in turn. In our case, the fleece yarn is elastomeric with high ability to be deformed before break. Thus, the looser structure of fleece pattern knit has higher ability for deformation at the point of puncture, while elastomeric fleece yarn prevents movement of adjacent stitches and hole formation.

\subsection{Abrasion Resitance}

An abrasion test was performed in order to find the resistance of the newly developed knitted fabrics to abrasion. The abrasion resistance was evaluated by the number of cycles until the hole was formed on the specimens' surface. Results of the test are presented in Figure 6.

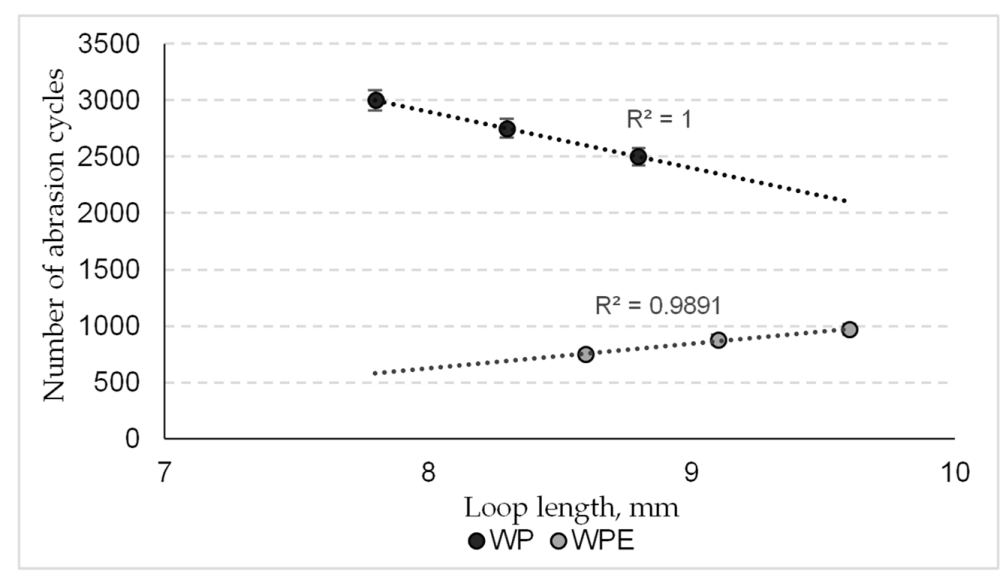

Figure 6. Abrasion resistance.

As it can be seen in Figure 6, the WP and WPE knits demonstrated different behaviour during the abrasion test and showed different resistance to abrasion. The samples of plain structure WP lasted from 2500 to 3000 cycles according to the loop length, and samples of a fleecy elastomeric structure WPE, respectively, from 750 to 970 cycles, which corresponds to the three and two protection levels according to EN 388:2003, respectively. The abrasion resistance of the plain structure WP decreases with increases in the loop length. Due to the increased loop length, the loop density in the fabric decreases. It is well known that the looser structure of a knit is less resistant to abrasion. The increase of the loop length by $11.4 \%$ leads to the decrease of abrasion resistance by $16.7 \%$. The elastomeric fleece structured knits WPE showed the inverse relationship due to presence of the elastomeric yarn 
in the knitted structure. For fabrics of this type the increase of the loop length by $10.4 \%$ leads to an increase in the abrasion resistance by $29.3 \%$. The introduction of the elastomeric yarn into the knitted structure results in formation of the relief surface, the convex part of which is first subjected to abrasion upon contact with the abrasive surface. Thus, the WP structure fabrics are more abrasion resistant.

\section{Conclusions}

Investigation of mechanical properties of two variants ultra-strong weft plain knits with and without elastomeric yarn in the structure, designed for personal protective equipment, showed dependence on structural parameters, which led to the following conclusions:

- An increase in the loop length of the weft plain knits with elastomeric tuck-miss laid yarn has approx. four times higher influence on the decrease of the breaking force and increases the elongation at the break when compared to weft plain knits without elastomeric yarn.

- The increase of the loop length influenced higher cut resistance. However, this influence for plain knits with elastomeric yarn is approx. three times lower than for knits without the elastomeric yarn.

- Tearing force of all investigated fabrics varied in the ranges of 217-227 N irrespectively of the tearing direction, knitting structure and differences in loop length. Moreover, samples break in the area of sample parts clamped into the top and bottom clamps while the main part of the sample remains not damaged.

- A decrease of a loop length in $1 \mathrm{~mm}$ can determine approx. $33 \%$ higher resistance to puncture of both plain knit variants, with and without the elastomeric yarn in the structure. However, plain knitted fabrics without the elastomeric yarn are more puncture resistant than fleece fabrics with elastomeric yarn because of different deformation abilities during the puncture.

- Abrasion resistance of the plain structure knits decreases with increases in the loop length, as the looser structure of a knit is less resistant to abrasion. However, the increase of the loop length of plain knits with elastomeric tuck-miss laid yarn leads to the increase in the abrasion resistance as the elastomeric yarn results formation of the relief surface, the convex part of which is first subjected to abrasion upon contact with the abrasive surface.

The results of this research show that elastomeric component has high influence on mechanical properties of knits and even more-it changes the principal mechanical behaviour of knits and character of structural parameters influence on the investigated properties. In the next stage of investigations, more variants of elastomeric yarn introduction into the knitted structure will be developed and mechanical and comfort properties of these knits will be analysed.

Author Contributions: Conceptualization, R.M., D.M. and L.H.; methodology, D.M., L.H. and S.B.; formal analysis, D.M., R.M. and L.H.; investigation, L.H., S.B. and T.I.; resources, L.H., S.B. and T.I.; data curation, D.M., and L.H.; writing — original draft preparation, D.M. and L.H.; writing-review and editing, R.M.; visualization, D.M. and L.H.; supervision, R.M. and L.H.; project administration, R.M. and L.H. All authors have read and agreed to the published version of the manuscript.

Funding: This research received no external funding.

Acknowledgments: This work was supported by the Lithuanian-Ukraine cooperation project "Knitted Materials for Personal Protective Equipment against Mechanical and Flame Damages (PERPROKNIT)" by the Research Council of Lithuania and Ministry of Education and Science of Ukraine.

Conflicts of Interest: The authors declare no conflict of interest.

\section{References}

1. Fangueiro, R.; Carvalho, R.; Silveira, D.; Ferreira, N.; Ferreira, C.; Monteiro, F.; Sampaio, S. Development of high-performance single layer weft knitted structures for cut and puncture protection. J. Textile. Sci. Eng. 2015, 5, 225-230.

2. Deniz, M.A.; Gamze, G.B. Sewability (Based on Needle Penetration Force) of $1 \times 1$ Rib Knitted Fabrics Produced with Separate Ends of Yarns. AUTEX Res. J. 2019, 19, 340-346. 
3. Ma, J.; Elmaaty, T.; Okubayashi, S. Effect of Supercritical Carbon Dioxide on Dyeability and Physical Properties of Ultra-High-Molecular-Weight Polyethylene Fiber. Autex Res. J. 2019, 19, 228-235. [CrossRef]

4. Guo, Z.; Martinez-Morales, S.; Chen, W. Projectile strength effects on the ballistic impact response of soft armor targets. Text. Res. J. 2020, 90, 282-293. [CrossRef]

5. Naveen, J.; Jawaid, M.; Zainudin, E.S.; Sultan, M.T.H.; Yahaya, R. Effect of graphene nanoplatelets on the ballistic performance of hybrid Kevlar/Cocos nucifera sheath-reinforced epoxy composites. Text. Res. J. 2019, 89, 4349-4362. [CrossRef]

6. Zhang, Y.D.; Wang, Y.L.; Huang, Y.; Wan, Y.Z. Preparation and properties of three-dimensional braided UHMWPE fiber reinforced PMMA composites. J. Reinf. Plast. Compos. 2006, 25, 1601-1609. [CrossRef]

7. Roylance, D.; Wilde, A.; Tocci, G. Ballistic impact of textile structures. Text. Res. J. 1973, 43, 34-41. [CrossRef]

8. Mikucioniene, D.; Arbataitis, E. Comparative Analysis of the Influence of Bamboo and Other Cellulose Fibres on Selected Structural Parameters and Physical Properties of Knitted Fabrics. Fib. Text. East. Eur. 2013, 21, 76-80.

9. Guo, N.; Sun, M.; Cheng, L.; Jiang, C.; Chen, W.; Jing, L. Strength characteristic and failure criterion of flexible multi-axial warp-knitted fabrics coated with polyurethane on single side. J. Indust. Text. 2019, 49, 318-327. [CrossRef]

10. Mikucioniene, D.; Ciukas, R.; Mickeviciene, A. The Influence of Knitting Structure on Mechanical Properties of Weft Knitted Fabrics. Mat. Scien.-Medzg. 2010, 16, 221-225.

11. Mikucioniene, D.; Milasiute, L.; Milasius, R. Influence of Knits Structure on Flammability and Comfortability. Autex Res. J. 2014, 14, 226-232. [CrossRef]

12. Krauledaite, J.; Ancutiene, K.; Urbelis, V.; Krauledas, S.; Sacevičiene, V. Development and evaluation of 3D knitted fabrics to protect against mechanical risk. J. Indust. Text. 2019, 49, 383-401. [CrossRef]

13. Hussainn, S.; Glombikova, V.; Akhtar, N.; Mazari, A.; Mansoor, T.; Khan, K. Liquid Moisture Transportation Properties of Functional Underwears: Part 1. Autex Res. J. 2019, 19, 97-103. [CrossRef]

14. Bivainyte, A.; Mikucioniene, D. Influence of Shrinkage on Air and Water Vapour Permeability of Double-Layered Weft Knitted Fabrics. Mat. Sci.-Medzg. 2012, 18, 271-274. [CrossRef]

15. Kiekens, P.; Jayaraman, S. Intelligent Textiles and Clothing for Balistic and NBC Protection. Technology at the Cutting Edge (NATO Science for Peace and Security Series B: Physics and Biophysics); Springer: Dordrecht, The Netherlands; Berlin/Heidelberg, Germany, 2012; pp. 1-29.

16. Li, M.; Wang, P.; Boussu, F.; Soulat, D. Effect of Fabric Architecture on Tensile Behaviour of the High-Molecular-Weight Polyethylene 3-Dimensional Interlock Composite Reinforcements. Polymers 2020, 12, 1045. [CrossRef] [PubMed]

17. Abtewa, M.A.; Boussu, F.; Bruniauxa, P.; Loghinc, C.; Cristian, I. Ballistic impact mechanisms-A review on textiles and fibre-reinforced composites impact responses. Comp. Struct. 2019, 223, 110966. [CrossRef] 